\title{
《中国有色金属学报》编辑委员会
}

\section{Editorial Committee of The Chinese Journal of Nonferrous Metals}

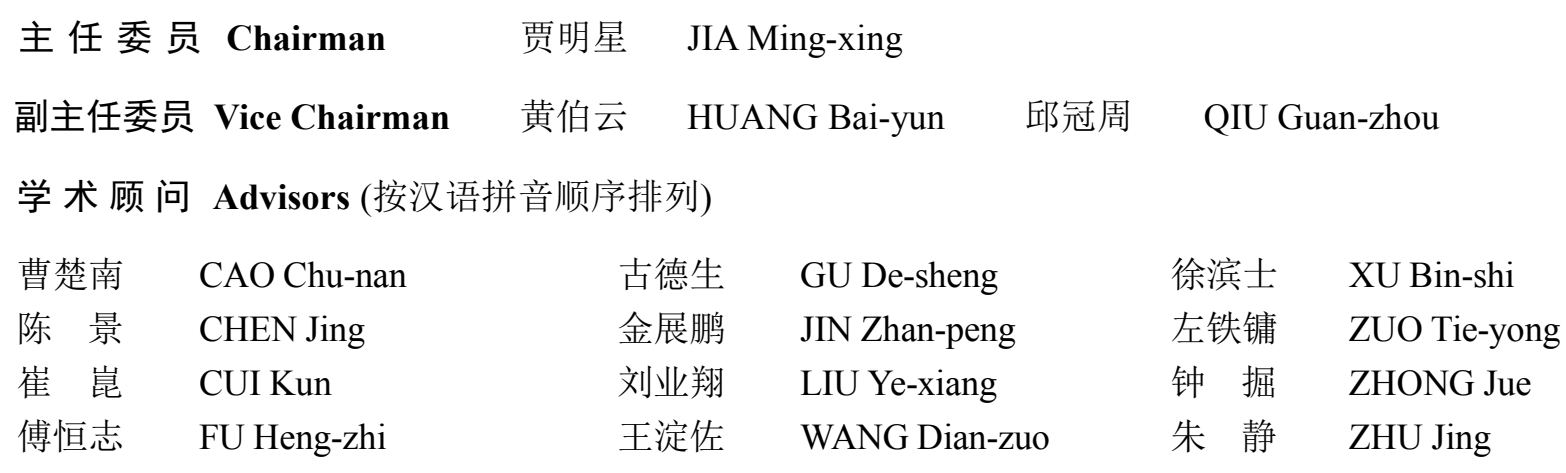

\section{委员 Members (按汉语拼音顺序排列)}

\begin{tabular}{|c|c|c|c|c|c|}
\hline 柴立元 & CHAI Li-yuan & 刘 咏 & LIU Yong & 易健宏 & YI Jian-hong \\
\hline 陈江华 & CHEN Jiang-hua & 刘永长 & LIU Yong-chang & 苑世剑 & YUAN Shi-jian \\
\hline 房文斌 & FANG Wen-bin & 鲁安怀 & LU An-huai & 曾光明 & ZENG Guang-ming \\
\hline 高焕芝 & GAO Huan-zhi & 鲁雄刚 & LU Xiong-gang & 曾小勤 & ZENG Xiao-qin \\
\hline 管仁国 & GUAN Ren-guo & 聂祚仁 & NIE Zuo-ren & 张平祥 & ZHANG Ping-xiang \\
\hline 关绍康 & GUAN Shao-kang & 潘复生 & PAN Fu-sheng & 张廷安 & ZHANG Ting-an \\
\hline 桂卫华 & GUI Wei-hua & 彭超群 & PENG Chao-qun & 张文海 & ZHANG Wen-hai \\
\hline 郭学益 & GUO Xue-yi & 彭金辉 & PENG Jin-hui & 赵中伟 & ZHAO Zhong-wei \\
\hline 韩恩厚 & HAN En-hou & 邱定蕃 & QIU Ding-fan & 钟 宏 & ZHONG Hong \\
\hline 韩雅芳 & HAN Ya-fang & 覃文庆 & QIN Wen-qing & 周克崧 & ZHOU Ke-song \\
\hline 韩跃新 & HAN Yue-xin & 孙宝德 & SUN Bao-de & 周科朝 & ZHOU Ke-chao \\
\hline 贺跃辉 & HE Yue-hui & 孙 军 & SUN Jun & 周 廉 & ZHOU Lian \\
\hline 何季麟 & HE Ji-lin & 孙 伟 & SUN Wei & 周 萍 & ZHOU Ping \\
\hline 胡文彬 & HU Wen-bin & 屠海令 & TU Hai-ling & 周益春 & ZHOU Yi-chun \\
\hline 华 林 & HUA Lin & 汪旭光 & WANG Xu-guang & 赵晓晨 & ZHAO Xiao-chen \\
\hline 黄小卫 & HUANG Xiao-wei & 王 华 & WANG Hua & 左 良 & ZUO Liang \\
\hline 姜 涛 & JIANG Tao & 王慧远 & WANG Hui-yuan & 吕 坚 & LÜ Jian \\
\hline 介万奇 & JIE Wan-qi & 王同敏 & WANG Tong-min & 王 健 & WANG Jian \\
\hline 李贺军 & LI He-jun & 魏炳波 & WEI Bing-bo & A. A. Luc & \\
\hline 李 劼 & LI Jie & 吴国华 & WU Guo-hua & A. B. Tse & lev \\
\hline 李金山 & LI Jin-shan & 吴玉程 & WU Yu-cheng & Christoph & M. Gourlay \\
\hline 李夕兵 & LI Xi-bing & 夏天东 & XIA Tian-dong & G. Gottst & \\
\hline 李 谦 & LI Qian & 谢建新 & XIE Jian-xin & H. Y. Soh & \\
\hline 李元元 & LI Yuan-yuan & 谢 锋 & XIE Feng & J. Hirsch & \\
\hline 梁叔全 & LIANG Shu-quan & 徐惠彬 & XU Hui-bin & Jung Il Sc & \\
\hline 刘 刚 & LIU Gang & 徐盛明 & XU Sheng-ming & P. Somas & daren \\
\hline 刘兴军 & LIU Xing-jun & 杨 斌 & YANG Bin & V. T. Zab & otny \\
\hline
\end{tabular}

